\title{
Effects of melatonin treatment on the physiological quality and cell wall metabolites in kiwifruit
}

\author{
Sen $\mathrm{CAO}^{1,2}(\mathbb{D})$, Guangfan $\mathrm{QU}^{1,2}$, Chao $\mathrm{MA}^{1,2}$, Liangjie $\mathrm{BA}^{1,2}$, Ning $\mathrm{JI}^{1,2}$, Lingshuai MENG ${ }^{1,2}$, Jiqing $\mathrm{LEI}^{1,2}$, \\ Rui WANG ${ }^{1,2 *}$
}

\begin{abstract}
We investigated the effects of melatonin (MT) treatment on the physiological quality and cell wall metabolism of kiwifruit during a 12-day shelf life period $\left(20 \pm 1{ }^{\circ} \mathrm{C}, 90 \pm 5 \% \mathrm{RH}\right)$, after 90 days of cold storage $\left(0 \pm 0.5^{\circ} \mathrm{C}, 90 \pm 5 \% \mathrm{RH}\right)$. Our results showed that MT treatment delayed kiwifruit softening, as evidence by the enhanced endurance of a healthy appearance, quality, color difference $\mathrm{L}^{*}$ value, and firmness of the fruit flesh. MT treatment reduced fruit decay rate, respiration rate, and malondialdehyde content; furthermore, MT-treated kiwifruit maintained high levels of total soluble solids, titratable acid, and ascorbic acid. Additionally, MT inhibited the decrease in fruit pectin, cellulose, and hemicellulose contents; it delayed the increase in watersoluble pectin content and kept pectin methyl esterase, polygalacturonase, cellulase, and $\beta$-galactosidase activities low. These results indicated that melatonin may have reduced the speed of softening of kiwifruit and preserved fruit quality by inhibiting enzymatic degradation of the cell wall, and by delaying pro-pectin, cellulose, and hemicellulose degradation, as well as the increase of water-soluble pectin content. These findings indicate that MT treatment may be an effective measure to delay kiwifruit postharvest cell-wall metabolism and preserve fruit quality.
\end{abstract}

Keywords: kiwifruit; shelf life; cold damage; fruit decay; enzymatic degradation.

Practical Application: Melatonin treatment can be used to extend kiwifruit shelf life.

\section{Introduction}

The new red-hearted 'Donghong' variety of yellow kiwifruit was bred at the Wuhan Botanical Garden of the Chinese Academy of Sciences. Due to its delicious flavor, high disease resistance and wide adaptability, as well as its high nutrient and antioxidant contents, 'Donghong' has been well accepted among consumers (Hu et al., 2014). Kiwifruit is a typical after-ripening fruit that quickly ripens after harvest and even deteriorates during storage at room temperature, as evidenced by softening, dehydration-induced shrinkage, and quality degradation observed under such conditions (Gwanpua, et al., 2018; Wang et al., 2020). Indeed, poor storage promotes cold damage, lignification, and water stains, among other problems. Therefore, ensuring the best storage conditions to allow for longer storage periods is particularly important to preserve the commercial value of kiwifruit. To date, the methods most commonly used for postharvest treatment and preservation of kiwifruit quality include: controlled-atmosphere storage (Daş et al., 2006), ozone (Lone et al., 2019), 1-MCP (Boquete et al., 2004), and plant-extract treatments (Pan et al., 2019). Nevertheless, more effective techniques are urgently needed to extend the shelf life of kiwifruit.

Melatonin (MT) is a plant ubiquitous, biologically active molecule that plays multiple functions, including, the modulation of plant growth and development, delaying of leaf senescence, hastening of fruit maturity, and reduction of cold damage in many horticultural crops (Gao et al., 2018; Hernández-Ruiz \& Arnao, 2018; Kong et al., 2020). Treatment with exogenous MT reportedly facilitates the maintenance of high glutathione and ascorbic acid contents, which in turn inhibits the expression of chlorophyll degradation-related genes, thereby delaying the senescence of apple leaves (Wang et al., 2012). Additionally, due to its antioxidant activity, MT treatment contributes to the removal of reactive oxygen species and enhances the plant antioxidant system and defense responses (Debnath et al., 2019). Moreover, MT can reduce browning of litchi and fresh-cut pears (Wang et al., 2020; Zheng et al., 2019); it delays the senescence of peaches, reduces the impact of cold damage on fruits (Cao et al., 2016; Gao et al., 2018; Meng et al., 2019), delays ripening of mangos and bananas (Hu et al., 2017) and reduces strawberry rot (Liu et al., 2018), thus preserving fruit quality in all cases studied. Consistently, it can also hinder the degradation of jujube cell-wall substances to prolong the fruit storage period (Tang et al., 2020). Nevertheless, there are few investigations on the modulation of cell wall metabolism by MT in kiwifruit.

Here, we explored whether MT treatment might contribute to preserve the quality of kiwifruit during shelf life. Specifically, 
we analyzed fruit flesh appearance, rot rate, fruit firmness, color difference $\mathrm{L}^{*}$ value, respiration intensity, and malondialdehyde (MDA), total soluble solids (TSS), titratable acidity (TA), and vitamin C contents. Simultaneously, we determined protopectin, water-soluble pectin, cellulose and hemicellulose, and pectin methylesterase (PME), polygalacturonase (PG), cellulase and $\beta$-galactosidase activities to identify the effects of MT on the metabolism of kiwifruit cell wall. Our findings will contribute significantly to the development of new postharvest treatments for extending the shelf life of kiwifruits and other horticultural fruits.

\section{Materials and methods}

\subsection{Fruit materials and treatments}

"Donghong" kiwifruits were collected from the experimental station in Liupanshui City, Guizhou Province. Kiwifruits without pest, disease or mechanical damage were selected and immersed in $0,50,100,200$, or $300 \mu \mathrm{M}$ MT solution for $15 \mathrm{~min}$. MT-treated fruits were then stored $30 \mathrm{~d}$ in a chromatography refrigerator at $20^{\circ} \mathrm{C}$ and $85 \%-95 \% \mathrm{RH}$. Three independent assays (each of which used 100 fruits) preliminarily confirmed that $200 \mu \mathrm{M}$ MT effectively delayed senescence of kiwifruits. In the second year, "Donghong" kiwifruits were acquired at the same experimental station. After collection, kiwifruits were immersed in a $200 \mu \mathrm{M}$ MT solution for $15 \mathrm{~min}$ and then dried naturally. Kiwifruits in the control (CK) group were immersed in distilled water for the same period of time. Then, all experimental fruits were wrapped in preservative film (PE20, $20 \mu \mathrm{m}$ thick) and stored 90 days in a mechanical refrigerator at $0 \pm 0.5^{\circ} \mathrm{C}$ and $90 \% \pm 5 \% \mathrm{RH}$. After this period, fruits were removed from the refrigerator, and a shelf life assay was conducted in a chromatography refrigerator at $20 \pm 1^{\circ} \mathrm{C}$ and $85 \%-95 \%$ RH. During the subsequent 12 -d storage period, the physiological indicators listed before were measured every $3 \mathrm{~d}$ as described below. Additionally, 10 kiwifruits were randomly selected for freezing under liquid nitrogen and stored at $-80^{\circ} \mathrm{C}$ to examine MDA, protopectin, water-soluble pectin, cellulose, and hemicellulose contents, and pectin methylesterase (PME), polygalacturonase (PG), cellulase and $\beta$-galactosidase activities.

\subsection{Decay rate, firmness, and $L^{\star}$ value}

Kiwifruit decay is easily identified by visible fungal growth, physical decay, and bacterial damage. The decay rate was defined as the number of fruits showing these signs of decay, expressed as a percentage relative to the total number of fruits in each treatment (Cao et al., 2016).

Fruit firmness was measured using a texture analyzer (TA. XT Plus C, Stable Micro Systems, UK) by the method reported by Braga et al. (2018), after slight modifications. Measurement parameters: the $\mathrm{P} / 2$ probe $(0.2 \mathrm{~mm}$ diameter $)$; pre-test, test, and post-test speeds were $2.0 \mathrm{~mm} / \mathrm{s}, 1 \mathrm{~mm} / \mathrm{s}, 2 \mathrm{~mm} / \mathrm{s}$; puncture depth was $10 \mathrm{~mm}$. Fruit firmness was expressed as $\mathrm{kg} \cdot \mathrm{cm}^{-2}$.

Fifteen intact, healthy fruits were selected from the treatment group and 15 more from the control group for measurement of the color of the fruit surface using a color-difference meter (CR-400, Konicaminolta, Japan) along the equator of the fruits. The $L^{\star}$ value indicates brightness or darkness (Liu et al., 2018).

\subsection{Respiratory rate and MDA content}

Ten fruits were randomly selected among MT-treated fruits and 10 more within the control group and sealed in a $3.0 \mathrm{~L}$ plastic container. After standing for $3 \mathrm{~h}$, fruit respiration rate was measured by a portable residual-oxygen analyzer (CheckPoint II, PBI Dansensor, Denmark). Each experiment included three parallel determinations. The respiratory rate was expressed as $\mathrm{CO}^{2} \cdot \mathrm{kg}^{-1} \cdot \mathrm{h}^{-1}$ (Onik et al., 2021).

The MDA content was measured according to the method of Onik et al. (2021) with slight modifications. Briefly, 3 g samples were added with $3 \mathrm{~mL}$ of $10 \%$ trichloroacetic acid for grinding, and then centrifuged at $10,000 \mathrm{rpm}$ for $15 \mathrm{~min}$ at $4{ }^{\circ} \mathrm{C}$. Then, $1.5 \mathrm{~mL}$ of the scavenger solution was mixed with an equal volume of thiobarbituric acid, placed in a boiling water bath for $30 \mathrm{~min}$ followed by rapid cooling and centrifugation at 10,000 rpm for $15 \mathrm{~min}$. The supernatant was then used for spectrophotometric (UV-2550, Shimadzu, Japan) measurement of $\mathrm{OD}_{450}, \mathrm{OD}_{532}$ and $\mathrm{OD}_{600}$. MDA content in kiwifruits was expressed on a fresh weight basis, as $\mathrm{mmol} \cdot \mathrm{g}^{-1}$.

\subsection{Total soluble solids and titratable acidity and ascorbic acid content}

Total soluble solids (TSS) content was measured by a PAl-1 Mini Digital refractometer (PAL-1, ATAGO, Japan) and expressed as percentage. In turn, fruit TA was measured after Yang et al. (2016), with slight modifications. Briefly, $3 \mathrm{~g}$ of kiwifruit tissue were ground in a mortar and transferred into a 100-mL volumetric flask; the mortar was rinsed with distilled water, which was then added to the flask prior to bringing to volume and shaking vigorously. After standing for $30 \mathrm{~min}$ the sample was filtered. Subsequently, $20.0 \mathrm{~mL}$ of this filtrate was withdrawn from the flask and transferred into a triangular flask, and two drops of $1 \%$ phenolphthalein indicator were added for titration with a calibrated sodium hydroxide solution. The end point of this titration was reached when the sample solution turned pink and did not fade within $30 \mathrm{~s}$. TA data were expressed as percent malic acid content.

Ascorbic acid content was determined by the method modified by Gao et al. (2016). Briefly, $5 \mathrm{~g}$ of kiwifruit tissue are added with a small amount of oxalic acid solution $\left(20 \mathrm{~g} \cdot \mathrm{L}^{-1}\right.$, ) ground into pulp under ice, transferred into a $100-\mathrm{mL}$ volumetric flask, and the volume brought to scale with the same oxalic acid solution. After standing for $10 \mathrm{~min}$, the solution was filtered and then $10 \mathrm{ml}$ of this filtrate was withdrawn and placed in a triangular flask. Titration was performed with 2,6-dichlorophenol indigo phenol solution, the end point of the titration was reached when the sample solution turned pink and did not fade within $30 \mathrm{~s}$. Results were expressed as mg of ascorbic acid per $100 \mathrm{~g}$.

\subsection{Protopectin, water soluble pectin, cellulose and hemicellulose}

Protopectin and water soluble pectin content was measured after Wang et al. (2020). First, a $100 \mu \mathrm{g} \mathrm{mL}^{-1}$ stock solution of galacturonic acid was prepared, from which, $0,0.2,0.4,0.6,0.8$, and $1.0 \mathrm{~mL}$ was placed in $25-\mathrm{mL}$ stoppered tubes and distilled 
water was added to bring them all to a final volume of $1 \mathrm{~mL}$. Then, $6.0 \mathrm{~mL}$ concentrated sulfuric acid was added to each tube before heating in a boiling water bath for $20 \mathrm{~min}$; after cooling to room temperature, $0.2 \mathrm{~mL}$ carbazole ethanol solution was added to each tube, and all were shaken well. After $2 \mathrm{~h}$ in the dark, the absorbance of the reaction solution was measured at $530 \mathrm{~nm}$. These absorbance readings were plotted against the known concentrations of galacturonic acid $(\mu \mathrm{g})$ to obtain a standard curve.

Water soluble pectin was determined as follows: 5-g kiwifruit tissue samples were ground in a mortar, transferred to a $50-\mathrm{mL}$ centrifuge tube, added with $25 \mathrm{~mL} 95 \%$ ethanol, placed in a boiling water bath for $10 \mathrm{~min}$, cooled at room temperature, and centrifuged at 10,000 rpm for $15 \mathrm{~min}$. These steps were repeated three times. Samples were precipitated in 25 -ml test tubes, added with $20 \mathrm{ml}$ distilled water, incubated in a water bath at $50^{\circ} \mathrm{C}$ for $30 \mathrm{~min}$, cooled down and centrifuged at 10,000 rpm for $15 \mathrm{~min}$. The supernatants was collected and dissolved with distilled water to $100 \mathrm{~mL}$. Finally, $1.0 \mathrm{~mL}$ of this sample solution was used to determine absorbance as described above for the standard curve.

Protopectin was determined as follows: After the aforementioned centrifugation, the sediment was kept in the centrifuge tube. The precipitate obtained was transferred to a $50 \mathrm{ml}$ tube, added with $50 \mathrm{ml}$ of sulfuric acid solution $\left(0.5 \mathrm{~mol} \mathrm{~L}^{-1}\right)$, boiled in water for $1 \mathrm{~h}$, cooled to room temperature and then filtered. The filtrate was collected and dissolved with distilled water to $100 \mathrm{~mL}$. Protopectin was measured in the same manner as water soluble pectin. Both protopectin and water-soluble pectin were expressed as a $\mathrm{mg} \cdot \mathrm{g}^{-1}$. The hemicellulose and cellulose fractions as carried out by the anthrone method (Wang et al., 2015). Results were expressed as $\mathrm{mg} \cdot \mathrm{g}^{-1}$.

\subsection{Enzyme activities}

Pectin methylesterase (PME) activity was measured by the method described by Santos et al. (2020). The reaction solution contained $2 \mathrm{~mL}$ of $0.5 \%$ pectin solution, $0.15 \mathrm{~mL}$ of $0.01 \%$ bromothymol blue, $0.85 \mathrm{~mL}$ of water, and $400 \mu \mathrm{L}$ of sample enzyme solution. Absorbance of the reaction solution was measured at $620 \mathrm{~nm}$. A unit of enzyme activity was defined as the amount of enzyme required to release $1 \mu \mathrm{mol}$ of methyl ester per minute. The experiment was repeated three times and the average value was calculated.

Polygalacturonase (PG), cellulase, and $\beta$-galactosidase activities were determined as in Chen et al. (2017). PG activity was assayed in a reaction mixture containing $0.5 \mathrm{~mL}$ of polygalacturonic acid solution $\left(10 \mathrm{~g} \cdot \mathrm{L}^{-1}\right)$ and $0.5 \mathrm{~mL}$ enzymatic extract. The absorbance of the reaction solution was measured at $540 \mathrm{~nm}$. In turn, Cellulase activity was determined in a reaction mixture containing $1.0 \mathrm{~mL}$ of $50 \mathrm{mM}$ acetate buffer ( $\mathrm{pH} 5.5$ ), $10 \mathrm{~g} \cdot \mathrm{L}^{-1}$ sodium carboxymethyl cellulose and $0.5 \mathrm{~mL}$ enzyme extract. Absorbance of the reaction solution was measured at $540 \mathrm{~nm}$. Finally, the determination of $\beta$-galactosidase activity used glucose as the standard product. Briefly, $0.5 \mathrm{~mL}$ of a polygalacturonic acid solution $\left(10 \mathrm{~g} \mathrm{~L}^{-1}\right)$ and $0.5 \mathrm{~mL}$ enzyme solution were incubated in a water bath at $37^{\circ} \mathrm{C}$ for $1 \mathrm{~h}$, after which, $1.5 \mathrm{~mL}$ of salicylic acid solution was added. The mixture was heated for $5 \mathrm{~min}$ in boiling water, then allowed to cool to room temperature before bringing the final volume to $25 \mathrm{~mL}$ with distilled water to measure absorbance at $540 \mathrm{~nm}$. Cellulase and $\beta$-galactosidase activities were expressed as $\mu \mathrm{g} \cdot \mathrm{h}^{-1} \cdot \mathrm{min}^{-1}$.

\subsection{Statistical analysis}

All statistical analyses were performed on at least three independent biological replicates. Data were analyzed using the originpro 8.0 software, and Duncan's new multi range test was performed by SPSS 22.0 to separate significantly different means. Statistical significance was set at $\mathrm{P}<0.05$.

\section{Results and discussion}

\subsection{Decay rate, firmness, and $L^{\star}$ value}

Figure 1 shows kiwifruit flesh appearance after a shelf period of $12 \mathrm{~d}$ under control and MT treatments. Fruit flesh in the CK group showed obvious lignification, water staining, and decay, whereas it remained intact in fruit of the MT-treated group. Kiwifruit decay rate showed an upward trend over the duration of the shelf-life experimental period (Figure 2A); furthermore, the decay rate was evidently higher in the CK group than in the MT-treated group $(P<0.05)$. At $12 \mathrm{~d}$ after the beginning of the experimental shelf-life period, the fruit decay rate of the CK group was $38.56 \%$, more than twice as high as that of the MT-treated group (17.24\%).

In contrast, the firmness of kiwifruit displayed a downward trend throughout the shelf life period (Figure 2B), at the beginning of which, the mean values for firmness of the CK and MT-treated groups were 6.82 and $7.76 \mathrm{~kg} \cdot \mathrm{cm}^{-2}$, respectively. However, after $12 \mathrm{~d}$, the firmness of the two groups decreased to 1.37 and $2.26 \mathrm{~kg} \cdot \mathrm{cm}^{-2}$, respectively. Although the $\mathrm{L}^{*}$ value for the CK group was higher than that for the MT-treated group over the entire shelf life period (Figure 2C), the difference between the two treatments was significant $(P<0.05)$ only on day 12 after shelf life initiation.

\subsection{Respiratory rate and MDA content}

Respiration rate is a crucial indicator of the effects of storage conditions. Normally, the higher the respiration rate is,

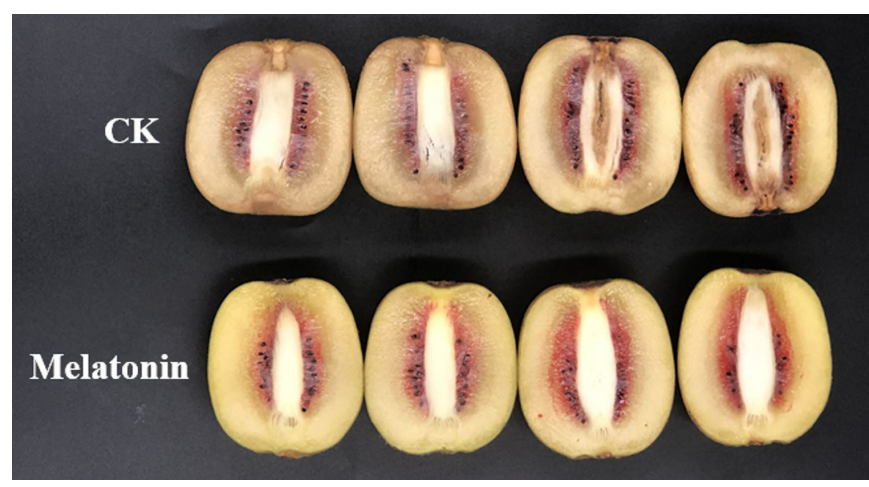

Figure 1. Effect of Melatonin and on fruit pulp of 'Donghong' Kiwifruit after 12 days of storage at $20^{\circ} \mathrm{C}$. CK is the control treatment. 

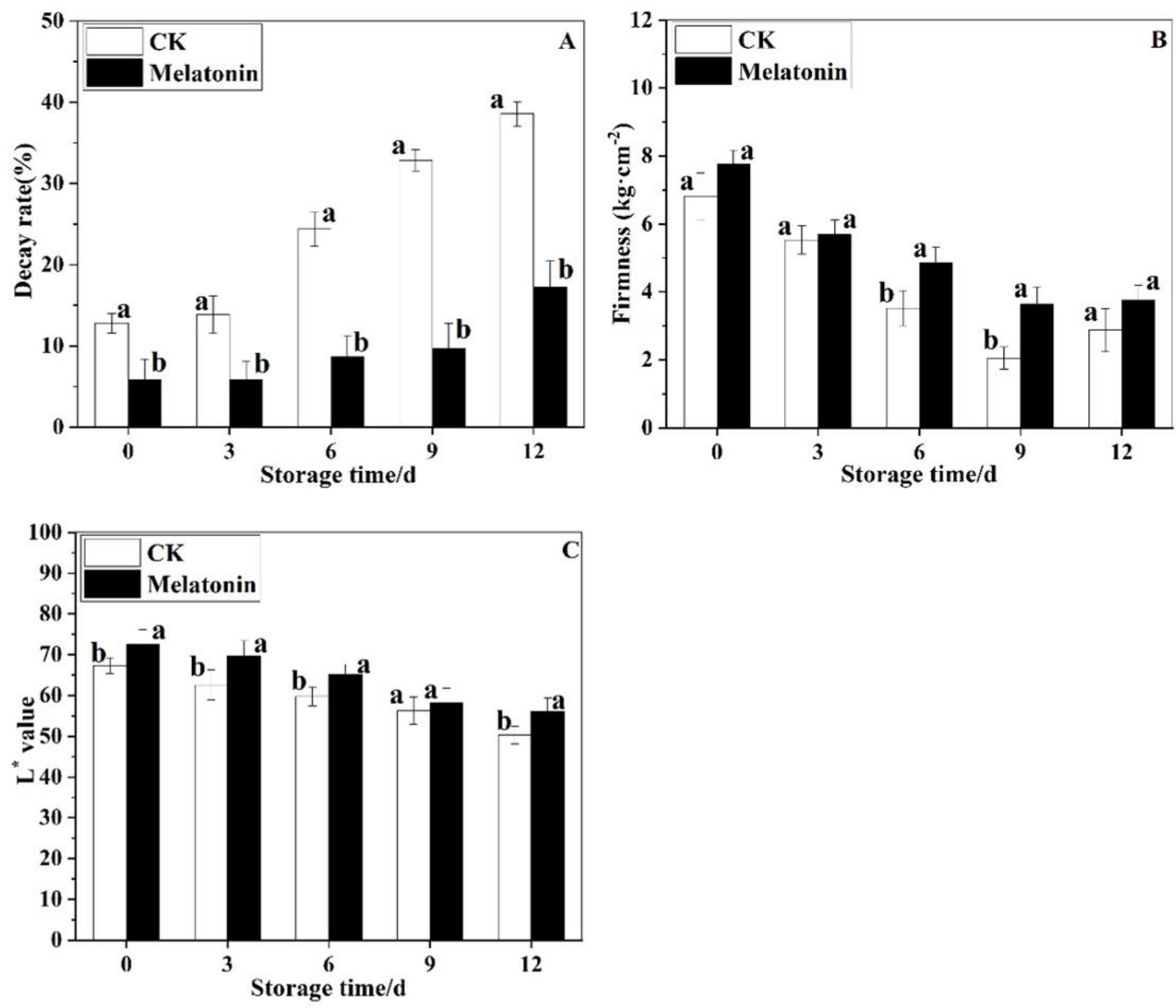

Figure 2. Effects of Melatonin on decay rate (A), fruit flesh firmness (B), and $L^{\star}$ value (C) in 'Donghong' Kiwifruit during storage for 12 days at $20^{\circ} \mathrm{C}$. Data are means and standard error of three biological replicates. Different letters indicate significant differences according to Student's t-test at $p<0.05$. CK is the control treatment

the more active metabolism is, and consequently, more of the nutrients in the fruit flesh are used. As shown in Figure 3A, the respiration rate of kiwifruits showed an initially increasing trend which peaked on day three and then became a decreasing one for the rest of the experimental shelf-life period. Further, fruit respiration rate was remarkably higher in the CK group than in the MT-treated group $(P<0.05)$. Indeed, at $12 \mathrm{~d}$ after shelf life initiation, the mean respiration rate in the MT-treated group was $33.12 \%$ lower than that in the CK group.

Malondialdehyde (MDA) is one of the main products of membrane lipid peroxidation, therefore, it is commonly used as a close proxy of the degree of aging in fruit and vegetable tissues, as its accumulation damages cellular organelles and plasma membranes. As shown in Figure 3B, the MDA content in kiwifruit showed an upward trend throughout the shelf-life experimental period and was markedly lower in the MT-treated than in the CK group $(P<0.05)$, and significantly, at $12 \mathrm{~d}$ after shelf life initiation the MDA contents of the CK and the MT groups were 1.17 and $0.57 \mathrm{mmol} \cdot \mathrm{g}^{-1}$, respectively.

\subsection{Total soluble solids, titratable acidity and ascorbic acid content}

Changes in the nutrient composition of the fruit during shelf life reflect the effects of storage. Figure 4A shows that at $6 \mathrm{~d}$ after storage, fruit TSS content peaked in both the CK and the MT-treated groups, and at $12 \mathrm{~d}$, TSS was $16.5 \%$ and $16.9 \%$, in the former and latter, respectively, with no significant $(P>0.05)$ differences observed. Titratable acid (TA) was higher 

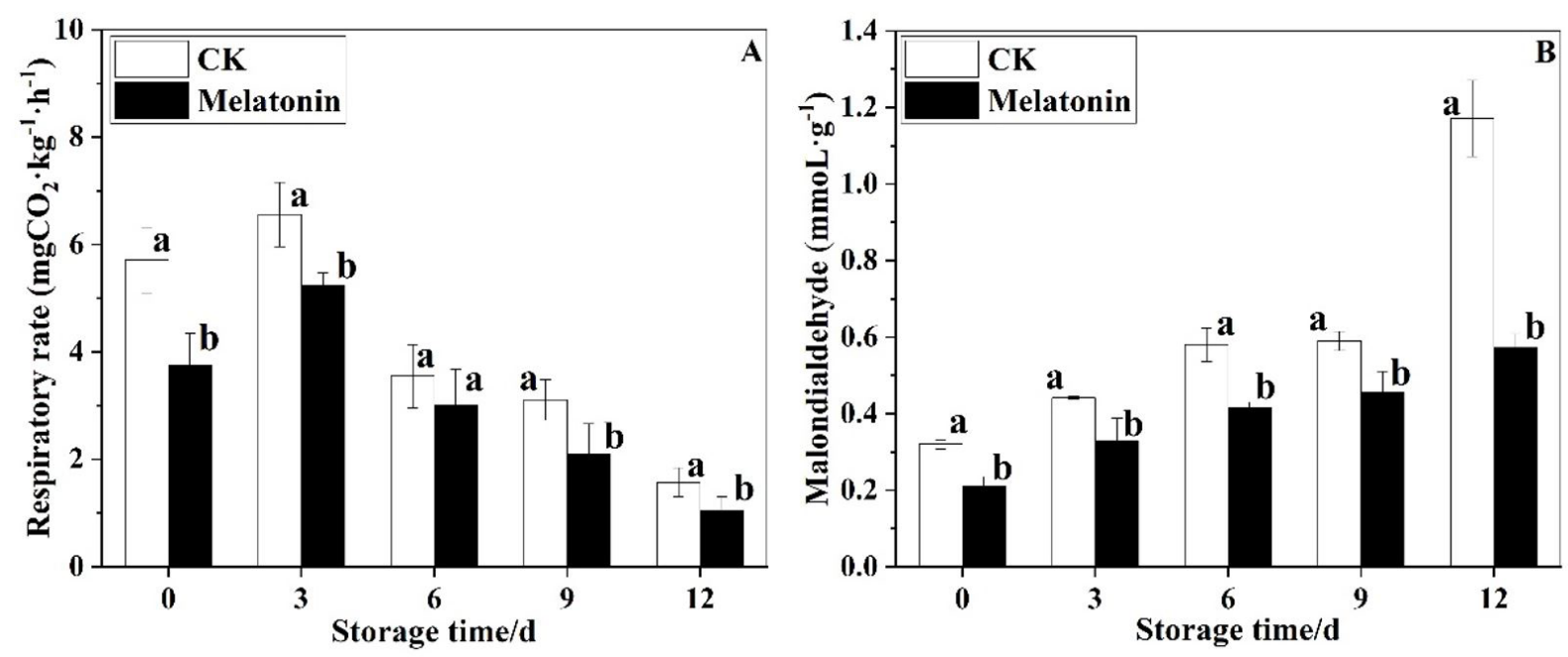

Figure 3. Effects of Melatonin on respiratory rate (A) and MDA content (B) in 'Donghong' Kiwifruit during storage for 12 days at $20{ }^{\circ} \mathrm{C}$. Data are mean and standard error values of three biological replicates. Different letters indicate significant differences according to Student's t-test at $p<0.05$. CK is the control treatment.
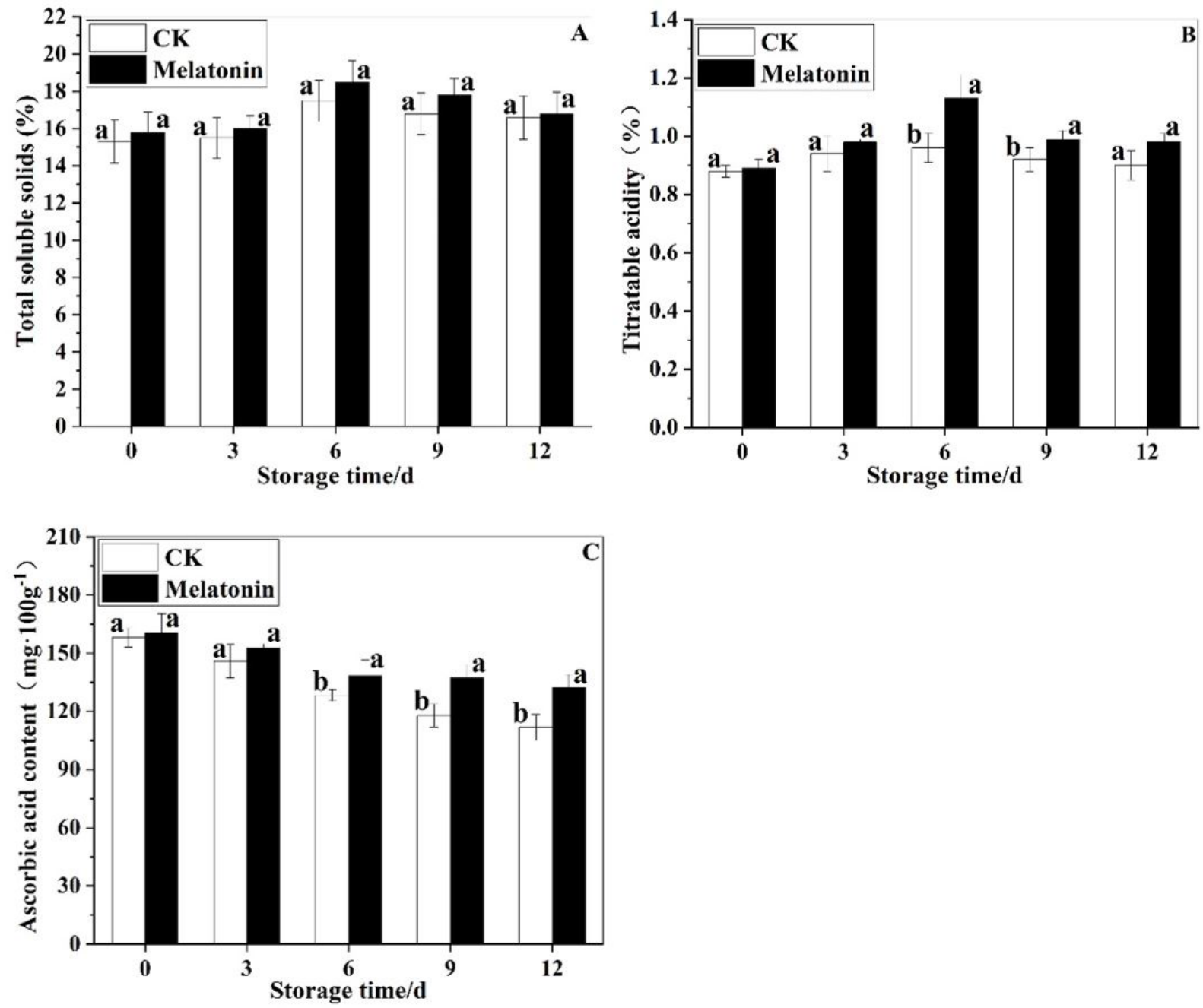

Figure 4. Effect of Melatonin on TSS (A), TA (B), and ascorbic acid content (C) in 'Donghong' Kiwifruit during storage for 12 days at $20{ }^{\circ} \mathrm{C}$. Data are mean and standard error values of three biological replicates. Different letters indicate significant differences according to Student's t-test at $p<0.05$. CK is the control treatment 
in fruits of the MT-treated group than in those of the CK group during the whole shelf life (Figure 4B). Concomitantly at $12 \mathrm{~d}$ after storage initiation, TA of the fruits was $0.88 \%$ and $0.92 \%$ in the MT-treated and the CK group, respectively, again, with no significant difference observed between the two $(P>0.05)$. As Figure 3C revealed, ascorbic acid content showed a downward trend throughout the shelf life period, at the beginning of which, ascorbic acid content was 158.06 and $160.15 \mathrm{mg} / 100 \mathrm{~g}$ for the CK and the MT-treated group, respectively. At $12 \mathrm{~d}$, ascorbic acid content was reduced by $29.31 \%$ in the CK group, whereas that of the MT-treated group was reduced by $17.29 \%$ only; moreover, according to Student's t-test $(P<0.05)$, the difference between the two groups at this point was significant.

\subsection{Protopectin and water soluble pectin}

Pectin is the main component of the cell wall. In the afterripening stage, protopectin is continuously hydrolyzed into soluble pectin under the action of pectinase and the fruit becomes increasingly soft. Figure 5A indicates that fruit protopectin showed a downward trend over the duration of the experimental period of shelf life. At $12 \mathrm{~d}$ after storage initiation, the protopectin content of the fruits were 0.14 and $0.17 \mathrm{mg} / \mathrm{g}$ in the CK and the MT-treated group, respectively, with the difference being significant $(P<0.05)$. Similarly, Figure 5B shows that throughout shelf life, water-soluble pectin in the fruits showed an upward trend. Additionally, at the beginning of storage, water-soluble pectin content in the CK group was only $0.04 \mathrm{mg} \cdot \mathrm{g}^{-1}$ higher than that of the MT group; however, at $12 \mathrm{~d}$ after storage initiation, water-soluble pectin content in the CK group was significantly $(P<0.05)$ higher than that in the MT group.

\subsection{Cellulose and hemicellulose}

Both cellulose and hemicellulose are major components of plant cell walls and the main substances responsible for the firmness of plant tissues. Consequently, the degradation of cellulose and hemicellulose during shelf life causes a decrease in fruit firmness. As shown in Figure 6A, there was no significant $(P>0.05)$ difference in cellulose content between the MT-treated and the CK group at the beginning and up to the third day of the experimental shelf-life period. However, from the sixth to the $12^{\text {th }}$ day of shelf life, fruit cellulose content of the MT group was significantly $(P<0.05)$ higher than that of the CK group. Similarly, as can be seen in Figure 6B, the hemicellulose content of the fruits of the MT group was higher than that of the CK group over the duration of the storage period, with the difference between the two groups being significant $(P<0.05)$ on day 12 of storage $(0.55 \%$ versus $0.64 \%$ hemicellulose for MT-treated and control kiwifruit, respectively).

\subsection{PME and PG activities}

As Figure 7A shows, PME activity generally increased in both fruit groups over the 12-d experimental storage period. From the beginning and up to day nine of storage, PME activity was significantly $(P<0.05)$ lower in fruit of MT-treated group than in that of the CK group; particularly, at $12 \mathrm{~d}$ after storage initiation, PME activity was 11.15 and $11.52 \mathrm{U} / \mathrm{min}^{-1}$, respectively. Consistently, PG activity of the CK group was higher than that of the MT group over the entire duration of the storage period (Figure 7B). Particularly, at $12 \mathrm{~d}$ after storage initiation, PG activity of the two groups (1.58 and $1.32 \mathrm{ug} / \mathrm{g} / \mathrm{min}$, respectively), were significantly different $(P<0.05)$.

\subsection{Cellulase and $\beta$-galactosidase activities}

Cellulase activity followed an increasing over the duration of the storage period and it was higher in the CK than in the MT group (Figure 8A). At $12 \mathrm{~d}$ after storage initiation, cellulase activity of the MT group was $12.59 \%$ lower than that of the CK group. In turn, from the beginning of shelf life and up to the
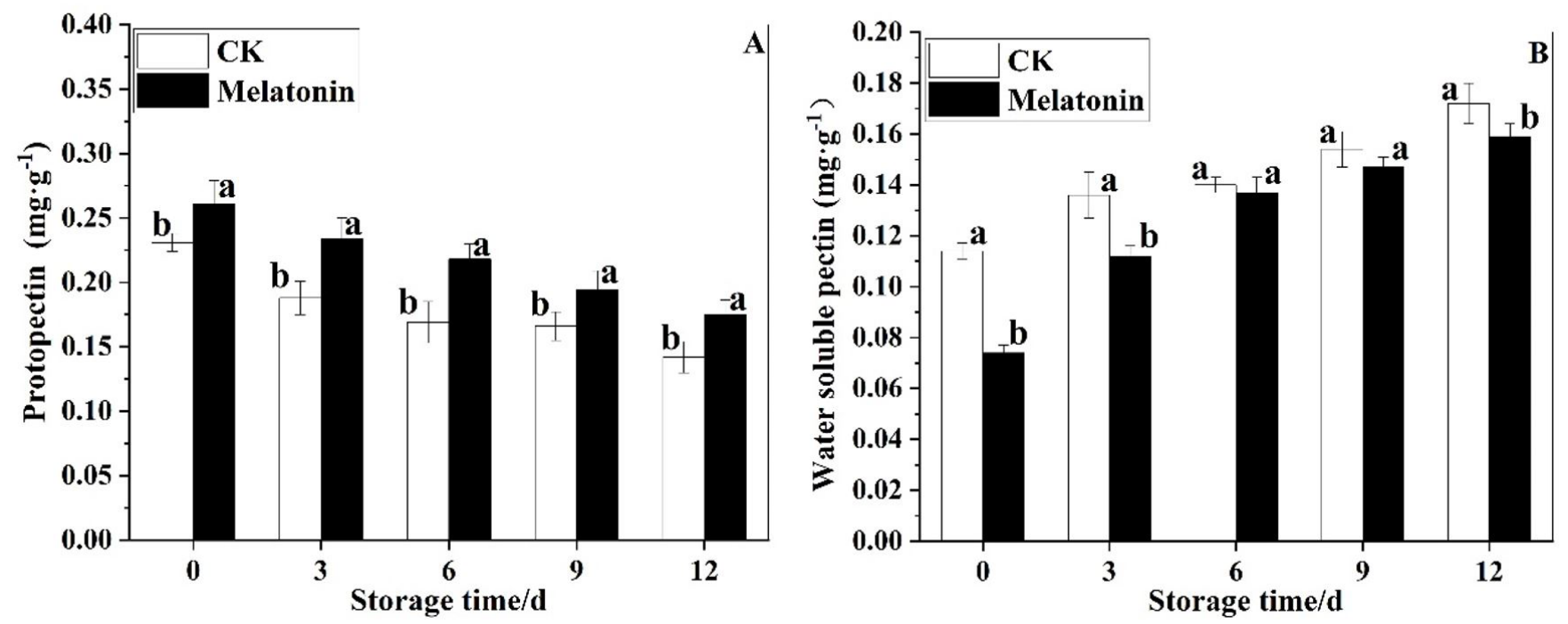

Figure 5. Effect of Melatonin on protopectin (A) and water-soluble pectin (B) of 'Donghong' Kiwifruit during storage for 12 days at $20{ }^{\circ} \mathrm{C}$. Data are mean and standard error values of three biological replicates. Different letters indicate significant differences according to Student's t-test at $p<0.05$. CK is the control treatment. 

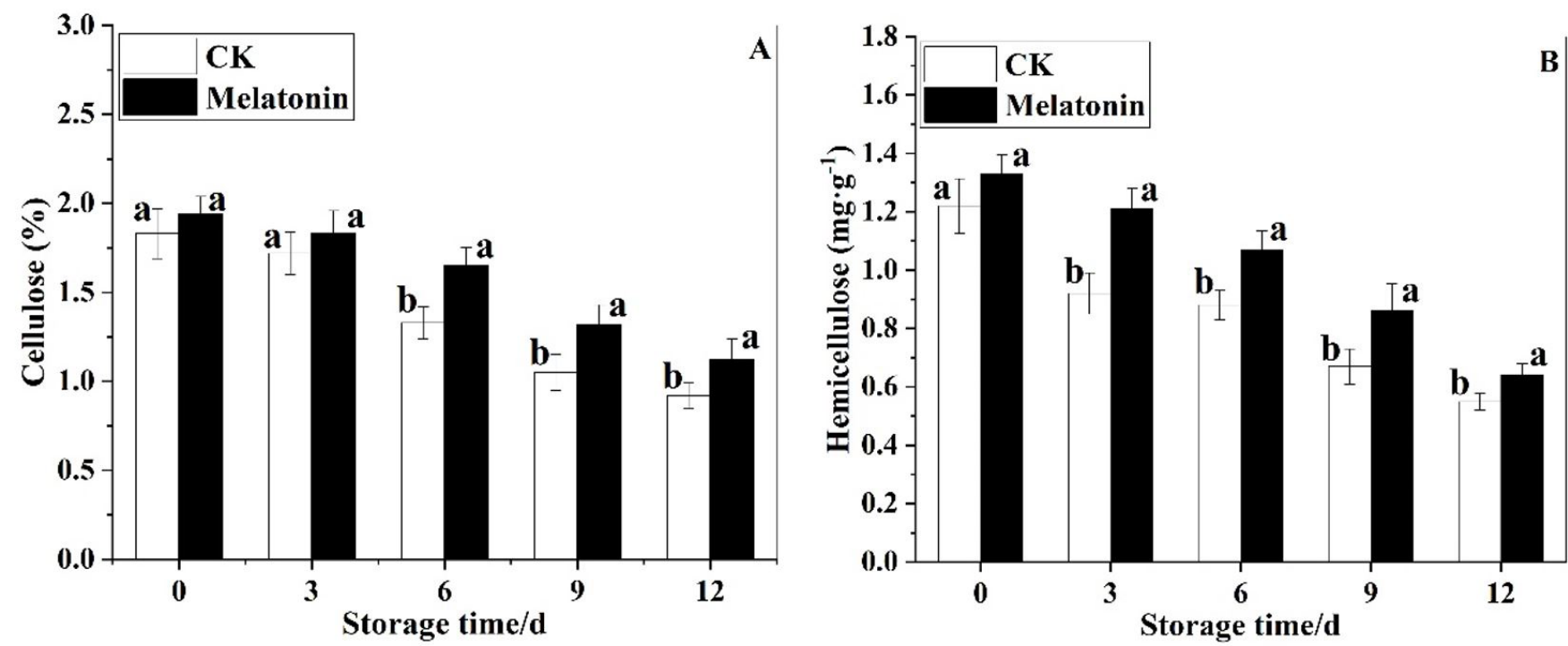

Figure 6. Effect of Melatonin on cellulose (A) and hemicellulose (B) content in 'Donghong' Kiwifruit during storage for 12 day at $20^{\circ} \mathrm{C}$. Data are mean values and standard errors of three biological replicates. Different letters indicate significant differences according to Student's t-test at $p<0.05$. CK is the control treatment.
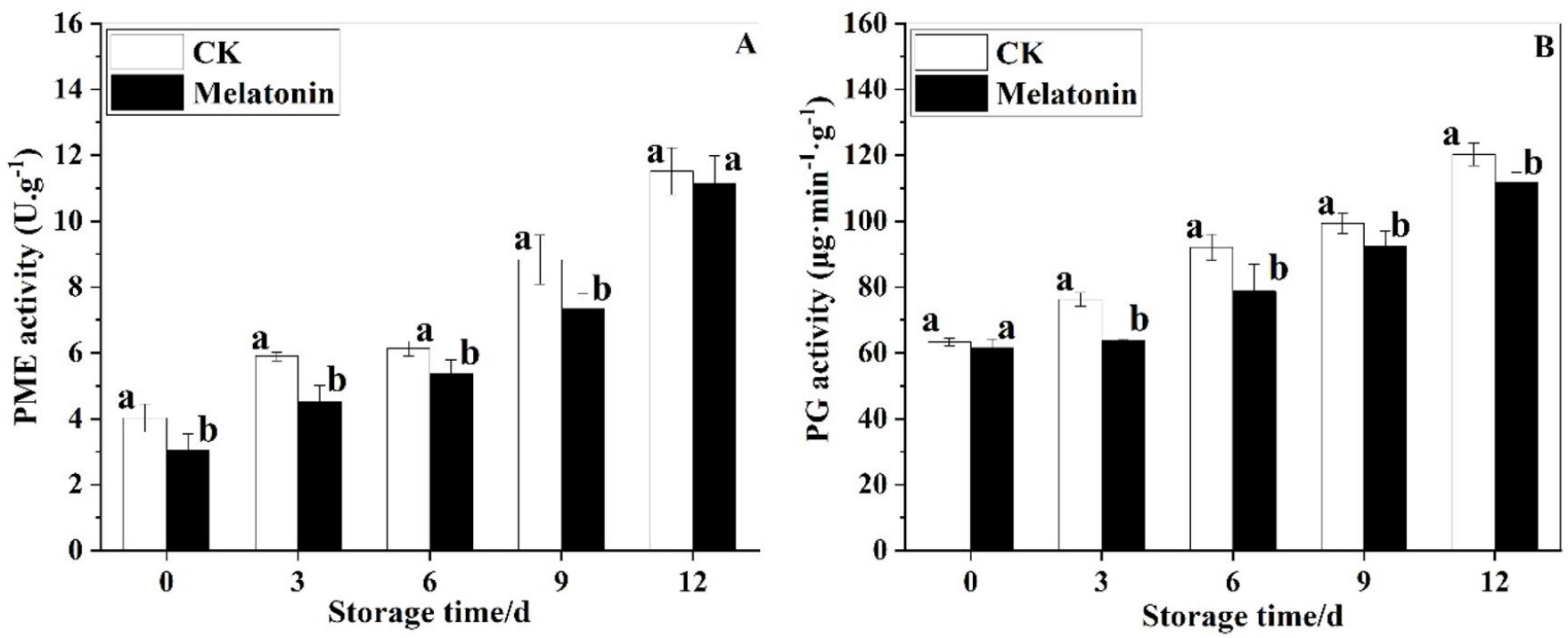

Figure 7. Effect of Melatonin on PME (A) and PG activity (B) of 'Donghong' Kiwifruit during storage for 12 days at $20^{\circ} \mathrm{C}$. Data are mean and standard error values of three biological replicates. Different letters indicate significant differences according to Student's t-test at $p<0.05$. CK is the control treatment.

third day, there was no significant $(P>0.05)$ difference in fruit $\beta$-galactosidase between the MT and CK groups (Figure $8 \mathrm{~B}$ ). From 6 to $12 \mathrm{~d}$ after storage initiation, fruit $\beta$-galactosidase activity of the MT group was significantly $(P<0.05)$ lower than that of the CK group; particularly, at $2 \mathrm{~d}$ of storage, $\beta$-galactosidase activity was 1.97 and $1.65 \mathrm{ug} / \mathrm{g} / \mathrm{h}$, respectively.

\section{Discussion}

The integrity of the cell wall is directly responsible for the firmness of fruit tissues, and the decrease in firmness is strongly associated with the activity of cell wall degrading enzymes
(Zhou et al., 2021). Fruit cell walls are mainly composed of macromolecules such as cellulose, hemicellulose, and pectin. These substances are crucial for maintaining fruit firmness (Abreu et al., 2012; Zhang, et al., 2018). The degradation of cell wall materials is reportedly a fundamental reason for the postharvest softening of fruits (Ireland et al., 2014; Li et al., 2021). Our study confirmed that fruit firmness was high at the beginning of the shelf life period; at which time the main components of fruit cell walls were cellulose and hemicellulose, while protopectin content was low. Furthermore, throughout the storage period, protopectin content decreased, whereas 

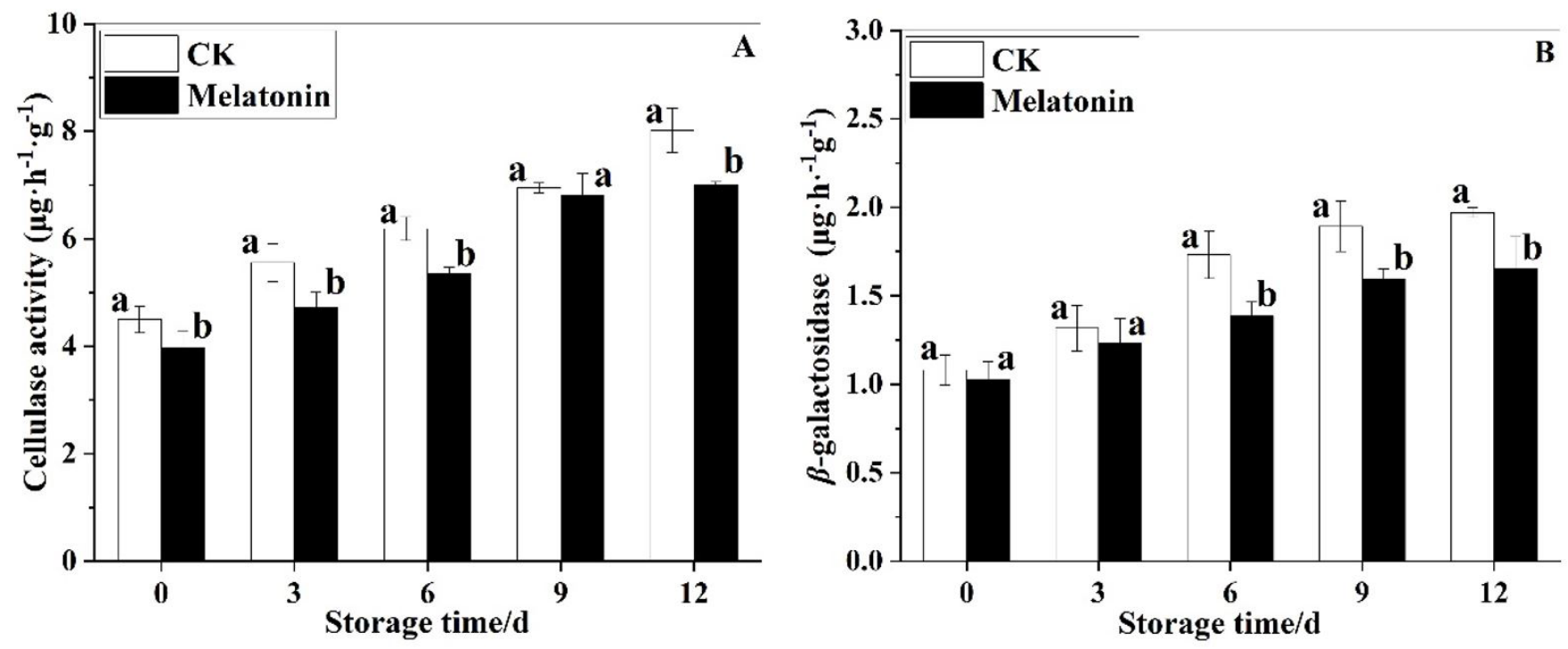

Figure 8. Effect of Melatonin on cellulase (A) and $\beta$-galactosidase (B) activities in 'Donghong' Kiwifruit during 12 days of storage at $20^{\circ} \mathrm{C}$. Data are mean and standard error values of three biological replicates. Different letters indicate significant differences according to Student's t-test at $p<0.05$. CK is the control treatment.

water-soluble pectin gradually increased. Concomitantly, fruit cellulose and hemicellulose contents gradually decreased due to enzymatic degradation, resulting in a decrease in fruit firmness, which accounted for the senescence and softening of kiwifruit in the later part of the experimental storage period.

Fruit softening results from cell-wall degrading enzyme activities (pectin methylesterase, polygalacturonase, cellulase and $\beta$-galactosidase) that catalyze the degradation of cell wall materials including pectin, cellulose, and hemicellulose (Cui et al., 2021; Hou et al., 2019). In this process, various cell wall degrading enzymes play different parts. Thus, PME mainly demethylates pectin, catalyzes the conversion of pectinic into pectic acid, and destroys calcium bridges between polysaccharide uronic-acid chains, thereby causing the separation of cells. Simultaneously, PME generates a substrate suitable for the action of PG. Furthermore, PME drives PG hydrolysis of pectic acid along the polygalacturonic acid backbone to degrade pectin, by breaking the 1,4-2-D-galactoside bond of polygalacturonic acid to hydrolyze it into galacturonic acid or galacturonic acid oligomers. Pectin degradation results in cell wall disintegration and fruit softening (Sun et al., 2013). Thus, the degradation of pectin is completed under the synergistic effect of PME and PG activities (Brummell et al., 2014).

Cellulase is a compound hydrolase that can degrade cellulose, thereby destroying the pectin-cellulose-hemicellulose structure of the cell wall (Carvajal et al., 2015). The function of $\beta$-galactosidase is mainly to break the galactosidic bonds in the cell wall materials and remove galactose residues, thus having an effect on the hydrolysis of pectin and hemicellulose (Lin et al., 2018). The results summarized herein showed that PME, PG, cellulase and $\beta$-galactosidase activities all followed an increasing trend throughout the shelf life period. Coupled with the degradation of the fruit cell walls and the hydrolysis of protopectin, kiwifruits gradually softened and eventually decayed. Hence, it can be concluded that fruit softening during shelf life is related to the degradation of cell wall materials, such as protopectin, cellulose, hemicellulose, by cell wall degrading enzymes including, pectin methylesterase, polygalacturonase, cellulase, and $\beta$-galactosidase.

As postharvest fruit senescence is related to cell wall degradation, technical measures are needed to inhibit postharvest enzymatic degradation of fruit cell walls and retard the degradation of the cell wall materials, thereby contributing to maintaining a high level of fruit firmness, delaying fruit softening, preserving stored fruit quality, and prolonging fruit shelf life (Lin et al., 2020; Ji et al., 2021; Yang et al., 202). Our findings suggest that fruit treatment with MT may effectively reduce postharvest PME, PG, cellulase, and $\beta$-galactosidase activities in kiwifruit, thereby inhibiting the degradation of fruit protopectin, cellulose and hemicellulose and the resulting accumulation of water-soluble pectin. MT treatment helped to maintain a higher fruit firmness and postpone the increase in fruit decay rate and MDA content, whereby kiwifruit maintained a high nutritional quality, and excellent pulp color and appearance (Figure 9). These findings are consistent with results reported by Tang et al. (2020) according to which, MT hindered the activity of jujube cell-wall degrading enzymes, thereby improving fruit storage quality.

In addition, the occurrence of cold damage in postharvest fruits is associated with the metabolism of cell wall materials (Brummell et al., 2004). Nevertheless, the response of cell-wall material metabolism to postharvest cold damage varies with the symptoms of cold damage in fruits and vegetables, which mainly include browning, lignification, and water staining of the flesh, which can foster fruit postharvest senescence (Loay \& Dawood, 2019; Zhao et al., 2019; Zhang et al., 2020). A previous study revealed that a significant increase in PG and PME 


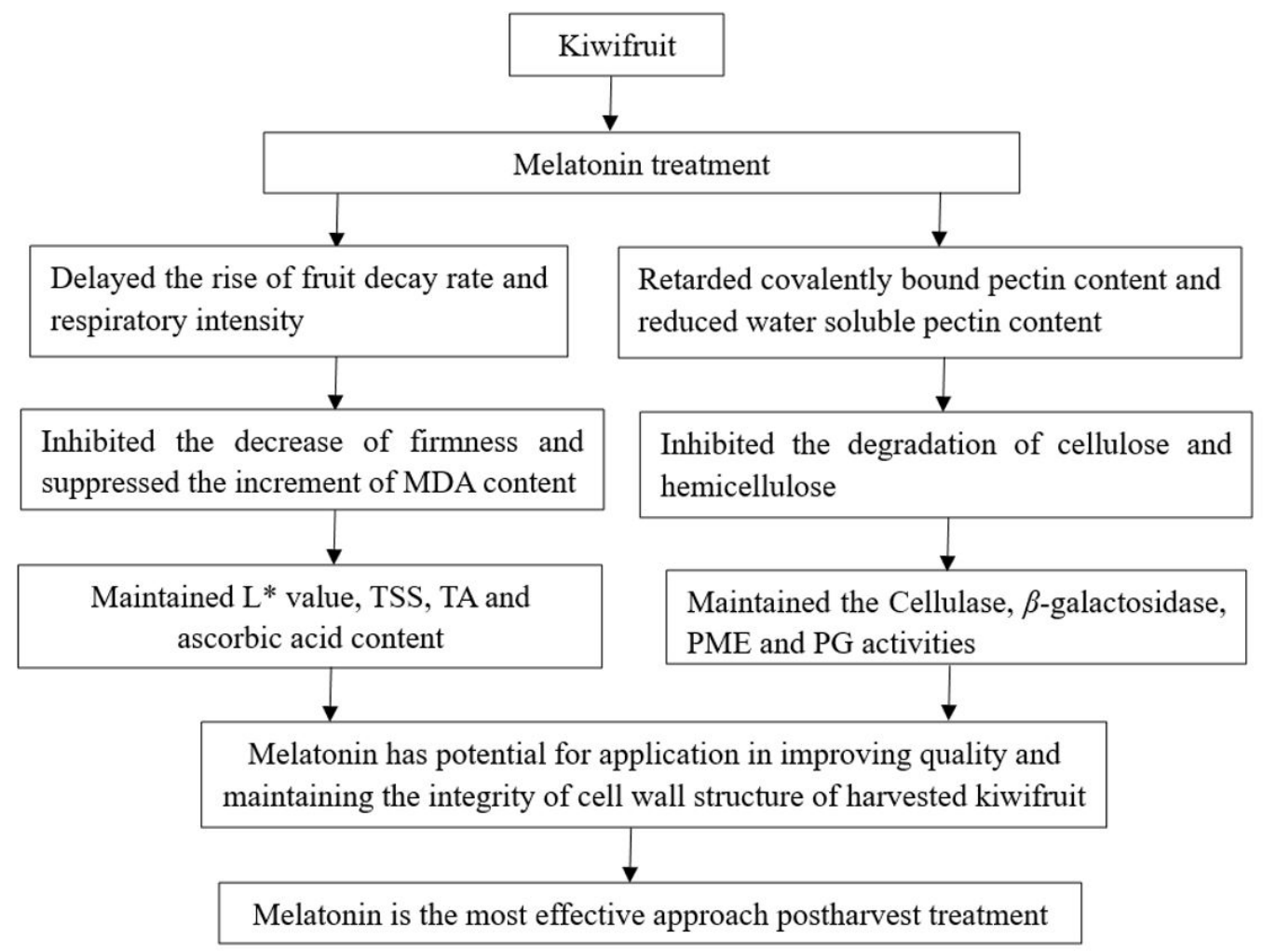

Figure 9. Hypothetical mechanism proposed to account for the melatonin-induced preservation of postharvest kiwifruit-quality preservation during storage through the control of cell wall metabolism.

activities was positively correlated with fruit cold-damage index (Carvajal et al., 2015). A study on loquats (Eriobotrya japonica) by Cao et al. (2010) proved that the main symptom of cold damage in loquats was their deterioration due to lignification. Cold damage can disrupt the balance between PME and PG activities in loquats, maintain low water soluble pectin content, hasten the increase of hemicellulose and cellulose contents, and eventually lead to a decrease in fruit juice yield and an increase in firmness. In this study, kiwifruit in the CK group showed water staining, browning, and other cold damage symptoms, whereas fruit in the MT-treated group did not develop any cold damage symptoms (Figure 1). Consistently with our results, MT can reportedly induce an increase in the expression of antioxidant genes $V c A P X, V c G S T$, and $V c P A L$, while reducing the peroxidation of membrane lipids in blueberries, thereby delaying the occurrence of cold damage (Shang et al., 2021). Similarly, Wang et al. (2021) showed that treatment with MT induced the expression of miR528, resulting in the suppression of potential target genes MaPPO1, MaPPO2, and MaPPO3, which in turn fostered the accumulation of phospholipids and unsaturated fatty acids in banana fruits, reducing the browning of the peel and improving the ability of the fruits to resist cold stress. Nevertheless, the mechanism by which MT reduces cold damage in kiwifruits warrants further investigation.

\section{Conclusions}

Altogether, the findings reported herein clearly demonstrated that treatment with exogenous MT reduced fruit softening and preserved kiwifruit quality during storage by suppressing cellwall degrading enzyme activity and delaying the degradation of protopectin, cellulose, and hemicellulose, as well as the increase of water-soluble pectin. However, regarding our conclusion that MT reduces the cell wall metabolism of postharvest fruits to maintain fruit shelf-life quality, molecular studies are still the current priority to thoroughly clarify the mechanism underlying the observed MT effects.

\section{Acknowledgments}

This work was financially supported by Guizhou Province Key technology research and development and application of innovation base for agricultural products primary processing (QikeZhongYinDi [2020] 4018). This work was financially supported by the scientific research funds of Guiyang University [GYU-KY-(2022)].

\section{References}

Abreu, J. R., Santos, C. D., Abreu, C. M. P., Corrêa, A. D., \& Lima, L. C. (2012). Sugar fractionation and pectin content during the ripening of guava cv. Pedro Sato. Food Science and Technology (Campinas), 32(1), 156-162. http://dx.doi.org/10.1590/S0101-20612012005000029.

Boquete, E. J., Trinchero, G. D., Fraschina, A. A., Vilella, F., \& Sozzi, G. O. (2004). Ripening of 'Hayward' kiwifruit treated with 1-methylcyclopropene after cold storage. Postharvest Biology and Technology, 32(1), 57-65. http://dx.doi.org/10.1016/j.postharvbio.2003.09.013. 
Braga, M. A., Marques, T. R., Simao, A. A., Botelho, L. N. S., Oliveira, L. S., \& Abreu, C. M. P. (2018). Mechanism of firmness loss in guava cv. Pedro Sato during ripening at room temperature. Food Science and Technology (Campinas), 38(1), 26-32. http://dx.doi. org/10.1590/1678-457x.35416.

Brummell, D. A., Dal Cin, V., Crisosto, C. H., \& Labavitch, J. M. (2014). Cell wall metabolism during maturation, ripening and senescence of peach fruit. Journal of Experimental Botany, 55(405), 2029-2039. PMid:15286150.

Brummell, D. A., Dal Cin, V., Lurie, S., Crisosto, C. H., \& Labavitch, J. M. (2004). Cell wall metabolism during the development of chilling injury in cold-stored peach fruit: association of mealiness with arrested disassembly of cell wall pectins. Journal of Experimental Botany, 55(405), 2041-2052. http://dx.doi.org/10.1093/jxb/erh228. PMid:15310820.

Cao, S. F., Song, C. B., Shao, J. R., Bian, K., Chen, W., \& Yang, Z. (2016). Exogenous melatonin treatment increases chilling tolerance and induces defense response in harvested peach fruit during cold storage. Journal of Agricultural \& Food Chemistry, 64(25), 5215-5222. https: //doi. org/10.1021/acs.jafc.6b01118.

Cao, S. F., Zheng, Y. H., Wang, K. T., Rui, H. J., \& Tang, S. S. (2010). Effect of methyl jasmonate on cell wall modification of loquat fruit in relation to chilling injury after harvest. Food Chemistry, 118(3), 641-647. http://dx.doi.org/10.1016/j.foodchem.2009.05.047.

Carvajal, F., Palma, F., Jamilena, M., \& Garrido, D. (2015). Cell wall metabolism and chilling injury during postharvest cold storage in zucchini fruit. Postharvest Biology and Technology, 108, 68-77. http:// dx.doi.org/10.1016/j.postharvbio.2015.05.013.

Chen, Y. H., Hung, Y. C., Chen, M. Y., \& Lin, H. T. (2017). Effects of acidic electrolyzed oxidizing water on retarding cell wall degradation and delaying softening of blueberries during postharvest storage. Lebensmittel-Wissenschaft + Technologie, 84, 650-657. http://dx.doi. org/10.1016/j.lwt.2017.06.011.

Cui, K. B., Yang, L. L., Shu, C., Liu, J., Zhu, Z. J., Yang, Z. Q., Zhu, X., \& Jiang, W. B. (2021). Near freezing temperature storage alleviates cell wall polysaccharide degradation and softening of apricot (Prunus armeniaca L.) fruit after simulated transport vibration. Scientia Horticulturae, 288, 110296. http://dx.doi.org/10.1016/j. scienta.2021.110296.

Daş, E., Gürakan, G. C., \& Bayındırlı, A. (2006). Effect of controlled atmosphere storage, modified atmosphere packaging and gaseous ozone treatment on the survival of Salmonella enteritidis on cherry tomatoes. Food Microbiology, 23(5), 430-438. http://dx.doi. org/10.1016/j.fm.2005.08.002. PMid:16943034.

Debnath, B., Islam, W., Li, M., Sun, Y., Lu, X. C., Mitra, S., Hussain, M., Liu, S., \& Qiu, D. (2019). Melatonin mediates enhancement of stress tolerance in plants. International Journal of Molecular Sciences, 20(5), 1040. http://dx.doi.org/10.3390/ijms20051040. PMid:30818835.

Gao, H., Lu, Z. M., Yang, Y., Wang, D. D., Yang, T., Cao, M. M., \& Cao, W. (2018). Melatonin treatment reduces chilling injury in peach fruit through its regulation of membrane fatty acid contents and phenolic metabolism. Food Chemistry, 245, 659-666. http://dx.doi. org/10.1016/j.foodchem.2017.10.008. PMid:29287423.

Gao, H., Zhang, Z. K., Chai, H. K., Cheng, N., Yang, Y., Wang, D. N., Yang, T., \& Cao, W. (2016). Melatonin treatment delays postharvest senescence and regulates reactive oxygen species metabolism in peach fruit. Postharvest Biology and Technology, 118, 103-110. http:// dx.doi.org/10.1016/j.postharvbio.2016.03.006.

Gwanpua, S. G., Jabbar, A. J., Zhao, M., Heyes, J. A., \& East, A. R. (2018). Investigating the potential of dual temperature storage as a postharvest management practice to mitigate chilling injury in kiwifruit. International Journal of Refrigeration, 86, 62-72. http:// dx.doi.org/10.1016/j.ijrefrig.2017.12.004.

Hernández-Ruiz, J., \& Arnao, M. B. (2018). Relationship of melatonin and salicylic acid in biotic/abiotic plant stress responses. Agronomy (Basel), 8(4), 33. http://dx.doi.org/10.3390/agronomy8040033.

Hou, Y., Wu, F., Zhao, Y., Shi, L., \& Zhu, X. (2019). Cloning and expression analysis of polygalacturonase and pectin methylesterase genes during softening in apricot (prunus armeniaca l.) fruit. Scientia Horticulturae, 256, 108607-108607. http://dx.doi.org/10.1016/j. scienta.2019.108607.

Hu, H., Li, P., Wang, Y. \& Gu, R. (2014). Hydrogen-rich water delays postharvest ripening and senescence of kiwifruit. Food Chemistry, 156(1), 100-109. http://dx.doi.org/10.1016/j.foodchem.2014.01.067. PMid:24629944.

Hu, W., Yang, H., Tie, W., Yan, Y., Ding, Z., Liu, Y., Wu, C., Wang, J., Reiter, R. J., Tan, D. X., Shi, H., Xu, B., \& Jin, Z. (2017). Natural variation in banana varieties highlights the role of melatonin in postharvest ripening and quality. Journal of Agricultural and Food Chemistry, 65(46), 9987-9994. http://dx.doi.org/10.1021/acs. jafc.7b03354. PMid:29077394.

Ireland, H. S., Gunaseelan, K., Muddumage, R., Tacken, E. J., Putterill, J., Johnston, J. W., \& Schaffer, R. J. (2014). Ethylene regulates apple (Malus $\times$ domestica) fruit softening through a dose-by-time dependent mechanism and through differential sensitivities and dependencies of cell wall-modifying genes. Plant \& Cell Physiology, 55(5), 10051016. http://dx.doi.org/10.1093/pcp/pcu034. PMid:24553848.

Ji, Y. R., Hu, W. Z., Liao, J., Xiu, Z. L., Jiang, A. L., Guan, Y. G., Yang, X. Z., \& Feng, K. (2021). Ethanol vapor delays softening of postharvest blueberry by retarding cell wall degradation during cold storage and shelf life-sciencedirect. Postharvest Biology and Technology, 177, 111538. http://dx.doi.org/10.1016/j.postharvbio.2021.111538.

Kong, X. M., Ge, W. Y., Wei, B. D., Zhou, Q., Zhou, X., Zhao, Y. B., \& Ji, S. J. (2020). Melatonin ameliorates chilling injury in green bell peppers during storage by regulating membrane lipid metabolism and antioxidant capacity. Postharvest Biology and Technology, 170, 111315. http://dx.doi.org/10.1016/j.postharvbio.2020.111315.

Li, M., Zhi, H. H., \& Dong, Y. (2021). The influence of pre- and postharvest 1-MCP application and oxygen regimes on textural properties, cell wall metabolism, and physiological disorders of late-harvest 'Bartlett' pears. Postharvest Biology and Technology, 173(2), 111429. http:// dx.doi.org/10.1016/j.postharvbio.2020.111429.

Lin, Y., Lin, H., Wang, H., Lin, M., Chen, Y., Fan, Z., Hung, Y. C., \& Lin, Y. (2020). Effects of hydrogen peroxide treatment on pulp breakdown, softening, and cell wall polysaccharide metabolism in fresh longan fruit. Carbohydrate Polymers, 242, 116427. http://dx.doi. org/10.1016/j.carbpol.2020.116427. PMid:32564850.

Lin, Y., Lin, Y., Lin, H., Lin, M., Li, H., Yuan, F., Chen, Y., \& Xiao, J. (2018). Effects of paper containing 1-MCP postharvest treatment on the disassembly of cell wall polysaccharides and softening in Younai plum fruit during storage. Food Chemistry, 264(30), 1-8. http://dx.doi.org/10.1016/j.foodchem.2018.05.031. PMid:29853352.

Liu, C. H., Zheng, H. H., Sheng, K. L., Liu, W., \& Zheng, L. (2018). Effects of melatonin treatment on the postharvest quality of strawberry fruit. Postharvest Biology and Technology, 139, 47-55. http://dx.doi. org/10.1016/j.postharvbio.2018.01.016.

Lo'ay, A. A., \& Dawood, H. D. (2019). Chilling injury, fruit color maturity stages, and antioxidant enzyme activities of lemon 'baladi cv' fruits under cold storage stress. Scientia Horticulturae, 257, 108676. http:// dx.doi.org/10.1016/j.scienta.2019.108676.

Lone, S. A., Raghunathan, S., Davoodbasha, M., Srinivasan, H., \& Lee, S. Y. (2019). An investigation on the sterilization of berry 
fruit using ozone: an option to preservation and long-term storage. Biocatalysis and Agricultural Biotechnology, 20, 101212. http://dx.doi. org/10.1016/j.bcab.2019.101212.

Meng, J. F., Yu, Y., Shi, T. C., Fu, Y. S., Zhao, T., \& Zhang, J. F. (2019). Melatonin treatment of pre-veraison grape berries modifies phenolic components and antioxidant activity of grapes and wine. Food Science and Technology (Campinas), 39(1), 35-42. http://dx.doi. org/10.1590/1678-457x.24517.

Onik, J. C., Wai, S. C., Li, A., Lin, Q., Sun, Q. Q., Wang, Z. D., \& Duan, Y. Q. (2021). Melatonin treatment reduces ethylene production and maintains fruit quality in apple during postharvest storage. Food Chemistry, 337, 127753. http://dx.doi.org/10.1016/j. foodchem.2020.127753. PMid:32777566.

Pan, L., Zhao, X., Chen, M., Fu, Y., Xiang, M., \& Chen, J. (2019). Effect of exogenous methyl jasmonate treatment on disease resistance of postharvest kiwifruit. Food Chemistry, 305(3), 125483. PMid:31610420.

Santos, M. B., Jacobi, S. S., Miñarro, M. C. A., Balsalobre, J. A. P., Guillén, A. A., \& Gorbe, M. I. F. (2020). Kinetic characterization, thermal and $\mathrm{pH}$ inactivation study of peroxidase and pectin methylesterase from tomato (Solanum betaceum). Food Science and Technology (Campinas), 40(Suppl. 1), 273-279. http://dx.doi.org/10.1590/fst.09419.

Shang, F. Z., Liu, R. L., Wu, W. J., Han, Y. C., Fang, X. J., Chen, H. J., \& Gao, H. Y. (2021). Effects of melatonin on the components, quality and antioxidant activities of blueberry fruits. LWT-Food Science \& Technology, 147, 111582. https://doi. org/10. 1016/j. lwt. 2021. 111582.

Sun, X., Yang, Q., Guo, W., Dai, L., \& Chen, W. (2013). Modification of cell wall polysaccharide during ripening of Chinese bayberry fruit. Scientia Horticulturae, 160, 155-162. http://dx.doi.org/10.1016/j. scienta.2013.05.048.

Tang, Q., Li, C., Ge, Y., Li, X., Cheng, Y., Hou, J., \& Li, J. (2020). Exogenous application of melatonin maintains storage quality of jujubes by enhancing anti-oxidative ability and suppressing the activity of cell wall-degrading enzymes. LWT-Food Science and Technology, 127, 109431. http://dx.doi.org/10.1016/j.lwt.2020.109431.

Wang, H., Chen, Y. H., Lin, H. T., Lin, M. S., Chen, Y. H., \& Lin, Y. F. (2020). 1-Methylcyclopropene containing-papers suppress the disassembly of cell wall polysaccharides in anxi persimmon fruit during storage. International Journal of Biological Macromolecules, 151, 723-729. http://dx.doi.org/10.1016/j.ijbiomac.2020.02.146. PMid:32068065.

Wang, L., Jin, P., Wang, J., Jiang, L. L., Shan, T. M., \& Zheng, Y. H. (2015). Effect of $\beta$-aminobutyric acid on cell wall modification and senescence in sweet cherry during storage at $20^{\circ} \mathrm{C}$. Food Chemistry, 175, 471-477. http://dx.doi.org/10.1016/j.foodchem.2014.12.011. PMid:25577108.

Wang, P., Yin, L. H., Liang, D., Li, C., Ma, F. W., \& Yue, Z. Y. (2012). Delayed senescence of apple leaves by exogenous melatonin treatment: toward regulating the ascorbate-glutathione cycle. Journal of Pineal Research, 53(1), 11-20. https: //doi. org/10.1111/j.1600079x.2011.00966.x.

Wang, Z. Q., Pu, H. L., Shan, S. S., Zhang, P., Li, J. K., Song, H. M., \& Xu, X. B. (2021). Melatonin enhanced chilling tolerance and alleviated peel browning of banana fruit under low temperature storage. Postharvest Biology and Technology, 179, 111571. http:// dx.doi.org/10.1016/j.postharvbio.2021.111571.

Yang, Q. Z., Wang, F., \& Rao, J. P. (2016). Effect of putrescine treatment on chilling injury, fatty acid compositions and antioxidant system in kiwifruit. PLoS One, 11(9), e0162159. http://dx.doi.org/10.1371/ journal.pone.0162159. PMid:27607076.

Zhang, L. F., Chen, F. S., Lai, S. J., Wang, H. J., \& Yang, H. (2018). Impact of soybean protein isolatechitosan edible coating on the softening of apricot fruit during storage. Lebensmittel-Wissenschaft + Technologie, 96, 604-611. http://dx.doi.org/10.1016/j.lwt.2018.06.011.

Zhang, W., Zhao, H., Jiang, H., Xu, Y., Cao, J., \& Jiang, W. (2020). Multiple 1-MCP treatment more effectively alleviated postharvest nectarine chilling injury than conventional one-time 1-MCP treatment by regulating ros and energy metabolism-sciencedirect. Food Chemistry, 330, 127256. http://dx.doi.org/10.1016/j.foodchem.2020.127256. PMid:32540529.

Zhao, H., Jiao, W., Cui, K., Fan, X., Shu, C., Zhang, W., Cao, J., \& Jiang, W. (2019). Near-freezing temperature storage enhances chilling tolerance in nectarine fruit through its regulation of soluble sugars and energy metabolism. Food Chemistry, 289, 426-435. http://dx.doi. org/10.1016/j.foodchem.2019.03.088. PMid:30955633.

Zheng, H. H., Liu, W., Liu, S., Liu, C. H., \& Zheng, L. (2019). Effects of melatonin treatment on the enzymatic browning and nutritional quality of fresh-cut pear fruit. Food Chemistry, 299:125116. http:// dx.doi.org/10.1016/j.foodchem.2019.125116.

Zhou, Q., Zhang, F., Ji, S. J., Dai, H. Y., Zhou, X., Wei, B. D., Cheng, S. C., \& Wang, A. D. (2021). Abscisic acid accelerates postharvest blueberry fruit softening by promoting cell wall metabolism. Scientia Horticulturae, 288, 110325. http://dx.doi.org/10.1016/j. scienta.2021.110325. 